\title{
Poesía, política y memoria en la Argentina kirchnerista. La colección de poesía Los Detectives Salvajes (2007-2015)
}

\author{
Poetry, politics and memory in the kirchnerism Argentina. The poetry \\ collection Los Detectives Salvajes (2007-2015)
}

\author{
Emiliano Tavernini*
}

\begin{abstract}
Resumen: El presente artículo intenta analizar la propuesta editorial de Los Detectives Salvajes (2007-2015), realizada por hijos de militantes políticos perseguidos antes y durante la última dictadura cívico-militar argentina (1976-1983). Especialmente nos detendremos en los efectos de sentido que produjo en la esfera pública la lectura por parte del ex presidente Néstor Kirchner de un poema de Joaquín Areta, militante político desaparecido que integra dicha colección. Veremos cómo este fenómeno contribuyó a posicionar a los autores de la formación cultural dentro del campo de la poesía argentina como los "poetas kirchneristas", definición que desmiente por reduccionista la trayectoria y las concepciones políticas de la mayoría de los integrantes, aunque es lógica si se tiene en cuenta que los editores plantean pensar una política de la literatura que rompe con consensos naturalizados inherentes al propio campo.
\end{abstract}

Palabras clave: Poesía argentina, genocidio, memoria, kirchnerismo

\begin{abstract}
The present article tries to analyze an editorial proposal made by sons of political activists persecuted during the last Argentine civic-military dictatorship (1976-1983). Especially we will stop in the effects of sense that produced in the public sphere the reading by the ex-President Néstor Kirchner of a poem of Joaquin Areta, disappeared political militant that integrates this collection. We will see how this
\end{abstract}

\footnotetext{
* Argentino, Profesor en Letras por la Universidad Nacional de La Plata. Becario inicial del Consejo Nacional de Investigaciones Científicas y Técnicas. Doctorando en Letras por la Universidad Nacional de La Plata con el tema de investigación "Literatura y memoria en la Argentina reciente. La poesía de hijos de militantes políticos perseguidos antes y durante la última dictadura militar" dirigido por la Dra. Margarita Merbilhaá y co-dirigido por la Dra. Sara Bosoer. Integrante de los Proyectos de Investigación: "Violencia, literatura y memoria en el campo literario latinoamericano de las últimas décadas" dirigido por la Dra. Teresa Basile y "Literatura argentina de la última década" dirigido por la Dra. Miriam Chiani, radicados en el Instituto de Investigaciones en Humanidades y Ciencias Sociales de la Facultad de Humanidades y Ciencias de la Educación de la UNLP, emilianotavernini@ gmail.com
} 
phenomenon contributed to position the authors of cultural formation within the field of Argentine poetry as the "Kirchnerist poets", a definition that denies reductionist the trajectory and political conceptions of the majority of the members, although it is logical if Is taken into account that the editors propose to think a politics of the literature that breaks with naturalized consensuses of the own field.

Keywords: Argentine poetry, genocide, memory, kirchnerismo

Recibido: 08/05/2017

Aceptado: 02/08/2017

\section{La construcción de un archivo poético: La colección de poesía Los Detectives Salvajes}

En el caso que nos ocupa, el proyecto editorial de Los Detectives Salvajes puede entenderse como una singular acción de memoria emprendida por hijos de militantes desaparecidos. Este proyecto se desarrolló en una colección de la editorial Libros de la Talita Dorada que reúne los escritos de poetas desaparecidos o asesinados durante la última dictadura cívico-militar (Carlos Aiub, Jorge Money, Rosa María Pargas, Joaquín Areta, Luis Elenzvaig, José Carlos Coronel), cuyos cuadernos y libros circularon durante largo tiempo como archivos familiares o de compañeros de militancia. Repuestos a la esfera pública estos escritos funcionan al modo de "territorios de memoria", tal como propone Ludmila Da Silva (2001), es decir a la manera de un territorio de relaciones sociales que dan cuenta de un "proceso de articulación entre los diversos espacios marcados y las prácticas de sujetos diversos que se involucran con la producción del archivo"1. Se intenta abordar así no un fenómeno estático, completo y determinado, sino que asistimos a una difuminación de los límites externos acerca de lo incluido y lo excluido, debido a un constante devenir interno de estas manifestaciones, es decir a las continuas negociaciones y renegociaciones que se producen en las interpretaciones que las abordan. Los familiares cedieron libretas a los editores con los escritos de militantes desaparecidos, mientras que los ex compañeros de trabajo ofrecieron realizar las presentaciones de los poemarios en lugares simbólicamente representativos de la vida de los poetas, por ejemplo, Aquello que no existe todavía de José Carlos Coronel fue presentado en una esquina de la ciudad de Tucumán en la que durante los '70 tuvo su sede la Juventud Peronista en la que militaba Coronel.

Mediante esta estrategia editorial, los editores buscan restituir la voz de los padres, negada física, política, pero también artísticamente, para realizar con posterioridad el proceso de la propia negación, una negación paradójicamente afirmativa, la cual permitiría la construcción de una identidad a partir de una expresión formal novedosa centrada en la

1 Dalmaroni, Miguel, "La obra y el resto (literatura y modos del archivo)" en TELAR. Revista del Instituto Interdisciplinario de Estudios Latinoamericanos, Facultad de Filosofía y Letras, Universidad Nacional de Tucumán, vol. 7, 2009, p. 21. 
propia experiencia. De manera complementaria, entonces, el catálogo está conformado por los poemarios o poemas reunidos en antología de hijos de militantes desaparecidos, asesinados o exiliados (Juan Aiub, Emiliano Bustos, Julián Axat, Nicolás Prividera, María Ester Alonso, Pablo Ohde, Alejandra Szir, Jorge Ignacio Areta, Verónica Sánchez Viamonte, Ramón Inama) ${ }^{2}$. Como señala Elizabeth Jelin estamos en presencia de emprendedores de memoria, en este caso, los hijos se involucran personalmente en su proyecto pero también comprometen a otros, generando participación y una tarea organizada de carácter colectivo ${ }^{3}$. En este sentido, la agencia de los sujetos no (re) presenta el pasado, sino que lo incorpora performativamente con el objetivo de buscar un sentido individual y contribuir a la reconstrucción de la trama social.

Esta colección instituye diferentes mecanismos de yuxtaposición que producen encuentros, o que fundan una tercera dimensión espacio-temporal, un entrelugar, que no se corresponde del todo ni con los '70 ni con los 2000. En los distintos poemarios de hijos de desaparecidos se configuran de manera recurrente tópicos que dan cuenta de una identidad en constante construcción, que establece un fuerte anclaje con ese pasado traumático. Escenas como el regreso a casa, el abandono, la búsqueda y la conversión del hijo en detective, el reclamo público; junto con el énfasis en lo íntimo y lo familiar permiten al yo lírico mantener contacto con figuras espectrales que funcionan como eje y condición de la vida presente.

Además, el proyecto permitió desempeñar un rol social y político, porque al facilitar un medio para llenar ese vacío dejado por la dictadura, acompañó a los familiares en el proceso de búsqueda y duelo, propiciando la transformación de la memoria individual y colectiva, mediante un proceso de búsqueda de verdad, justicia y de encuentro intergeneracional. Según Axat el impacto de la colección permitió volver a tejer vínculos entre los hijos, pero también entre las familias que rápidamente se pusieron en contacto con los editores:

luego del año 2007, se observó que son muchos los familiares de desaparecidos que cuentan con documentos literarios. Algunos de ellos se retraen por el propio duelo que les impide hablar del tema o dar a conocer el material; otros tienen temores o dudas sobre si dicho material pueda tener un valor meramente privado o anecdótico. También están los que tienen intenciones de dar ese material a la luz, pero tienen dificultad para pensar en una forma de difusión, o costearse la edición en soporte libro ${ }^{4}$.

En un documento en el que intentan definir las líneas de la colección, Juan Aiub y Julián Axat plantean los siguientes objetivos:

\footnotetext{
2 Ver una primera aproximación en Tavernini, Emiliano, "Procesos de recuperación y negación de la voz filial en las poéticas de hijos de desaparecidos. La colección de poesía Los Detectives Salvajes", Cuadernos de Aletheia $n^{\circ} 2$. H.I.J.O.S. 20 años, Universidad Nacional de La Plata, octubre 2016, p. 40-52.

3 Jelin, Elizabeth, Los trabajos de la memoria, Madrid, Siglo XXI, 2002, p. 48. La autora diferencia la idea de emprendedores de memoria de "militantes de memoria" utilizada por Henri Rousso y "empresa de memoria" de Annette Becker.

${ }^{4}$ Axat, Julián, "El hijo y el archivo" en $9^{\circ}$ Conferencia bianual de la International Association of genocide scholars “Genocidio, verdad, memoria y elaboración”, Universidad de Tres de Febrero, 2011, p. 3.
} 


\section{OBJETIVO GENERAL}

Construir una colección de libros que funcione como puente generacional a través de la palabra recuperada de los desaparecidos durante el terrorismo de Estado en la Argentina entre 1976-1983.

\section{OBJETIVOS ESPECÍFICOS}

Lograr la búsqueda y el hallazgo de documentos literarios para recuperar la memoria de los desaparecidos.

Editar y difundir los "documentos literarios" hallados.

Publicar cada libro bajo formato y tratamiento específico que permitan su fácil acceso $\mathrm{y}$ conocimiento a las nuevas generaciones de jóvenes.

Aunque consideran que "la colección no busca dar con niveles de excelencia, predomina el valor historiográfico y memórico-afectivo por sobre exigencias estéticas”, el material hallado es sometido a un minucioso estudio y selección, previo a su publicación, con el objetivo de dar con determinados parámetros estéticos.

Como remarca Da Silva, una de las particularidades de la generación de hijos de desaparecidos:

radica en que tuvieron que acercarse al problema del terrorismo de Estado a partir de la pregunta por la identidad: “¿quiénes somos? ¿quiénes eran nuestros padres? ¿qué querían? ¿qué pasó durante la dictadura? ¿por qué los mataron? Explicar y entender esas cuestiones por ellos mismos significó entrar en un mundo desconocido o parcialmente revelado por las contenidas 'versiones familiares'

La pulsión de archivo es rastreable en la mayoría de las biografías de hijos de militantes setentistas. El afecto se adhiere a objetos que pertenecieron a los padres y en particular las fotografías, cintas de video, cartas o diarios íntimos constituyen elementos fundamentales en las elaboraciones identitarias. Hay una necesidad de conocer la vida de los padres, pero también una fetichización de vestigios que funcionan como portales espacio temporales que permiten vislumbrar un encuentro imposible. Estas pulsiones de reunión son directamente proporcionales a la pulsión archivolítica o al trauma que recibieron las generaciones de la posdictadura respecto de ese pasado silenciado, negado o tergiversado.

La narración de los editores respecto del origen de la colección, funciona como una metonimia de las búsquedas que debieron emprender como generación. El 10 de junio de 1977, Carlos Aiub, geólogo y militante del Movimiento Revolucionario 17 de Octubre (M17) fue secuestrado en el centro de la ciudad de La Plata. Un día antes, habían secuestrado a su esposa, Beatriz Ronco, y a su hermano Ricardo Aiub, que también militaban en el M-17

\footnotetext{
${ }^{5}$ Da Silva, Ludmila, No habrá más flores en la tumba del pasado, La Plata, Ediciones Al Margen, 2001, p.262.
} 
en una casa de Los Hornos. La vivienda que Beatriz y Carlos alquilaban en Tolosa, cerca de la esquina de 528 y 19, fue allanada a los días. Las pertenencias que sobrevivieron al saqueo y al robo fueron a parar a Coronel Dorrego, Provincia de Buenos Aires, donde vivían los padres de Carlos. Ellos conservaron cada una de las cosas que recibieron: ropas, juguetes, papeles, documentación, trofeos de la adolescencia. Cuando el padre de Carlos Aiub falleció, en 1995, esas pertenencias pasaron a sus nietos, Juan y Ramón, que entonces realizaban sus estudios universitarios en La Plata. En una caja de zapatos los hermanos encontraron un cuaderno Éxito con 30 poemas escritos por su padre. Dado que son muy pocos los poemas que tienen tachaduras o correcciones y la letra es muy prolija, realizando un improvisado trabajo filológico concluyeron que se encontraban ante un escrito pasado en limpio de versiones previas. Incluso existen conjeturas de que en el allanamiento los grupos de tareas se llevaron otros cuadernos con más poemas.

Pues bien, con esta anécdota, vemos que los escritos recuperados y publicados por la Colección son el resto de un primer acto de interpretación crítica, el de los militares que no destruyeron lo que consideraban intrascendente, sin embargo, los cuadernos que sí robaron son un archivo literario que como huella sus hijos aún ansían reponer. Esto nos lleva a pensar en lo que señala Miguel Dalmaroni a propósito de Arlette Farge cuando dice que: “"el archivo no es un stock [y...] representa constantemente una carencia' porque cada contingencia que descubre abre una grieta en algún relato, versión, estereotipo o expectativa previa" $"$.

Tal como señalara Jacques Derrida en su célebre conferencia, luego convertida en libro Mal de archivo. Una impresión freudiana, respecto a la ambivalencia etimológica de 'archivo', por un lado, su sentido nomológico que remite a arkhé, al mandato, por otro lado, el arkheîon, el lugar de consignación, la residencia de los que mandan. Estos dos significado van a emerger y se van a poner de manifiesto en la colección, por un lado identificamos el mandato de memoria, la necesidad de reponer las voces de las tradiciones filiares que el Estado genocida silenció, junto con el mandato de la tradición emancipadora de los '70; por otra parte, el catálogo de la colección funciona como un hogar, en tanto trabajo de memoria que permite en su materialidad, al mismo tiempo, realizar el encuentro simbólico (imposible) entre padres e hijos, sujetos soberanos que se domicilian en los poemarios y que ordenan y confrontan tradiciones selectivas del campo poético argentino.

La construcción de este archivo contempla dos procesos de democratización de la palabra poética, complementarios, que acontecen en la Colección: facilitan el acceso a los poemarios de manera gratuita, mientras que amplían la convocatoria a nuevos poetas no vinculados previamente a los integrantes de la formación cultural. Por un lado, la decisión política, estética y ética de publicar los poemarios de los padres brinda la posibilidad de acceder a esas memorias y escrituras negadas por el biopoder, incluso los libros pueden descargarse gratuitamente en archivos pdf desde el blog de la editorial. Por otra parte, el proceso de archivación se va ampliando y ensanchando ya desde el segundo volumen, en la sucesión de las publicaciones no sólo aparecerán hijos de perseguidos políticos, sino también poetas nacidos durante la década de los '80-'90. En la solapa de desear y tener de

${ }^{6}$ Dalmaroni, Miguel, op. cit., p. 11. 
Juan González Mora leemos una primera redefinición del proyecto inicial: “con el título de la conocida novela de Roberto Bolaño damos nombre a esta colección, dedicada a la búsqueda de una palabra que alguna vez fue pensada y sentida desde lo social. Es también una forma de hacer homenaje a la prosa, narrativa o verso de quienes aún tienen la certeza de la herida abierta dejada en la escritura tras el último golpe militar".

En la solapa del volumen 12 virgencita de los muertos de Nicolás Correa, se va a producir otro desplazamiento, no sólo se pondrá de manifiesto la intención de recuperar la poesía silenciada por el Estado genocida, sino que también el proyecto "incluye la edición de poetas actuales, los que van y vienen con ese ayer, los perdidos, literales, huérfanos, menores, decadentes y malparidos por el neoliberalismo poético". Leemos en esta cita, un intento de ampliar o abrir los sentidos de la palabra hijos para dar cuenta de una grieta generacional que abarca a la sociedad argentina en su conjunto, en tanto heredera del genocidio. Es significativo que asistimos con estos desplazamientos, a una especie de reactualización de las tres opciones para definir la población integrante de H.I.J.O.S. en el momento de conformación del Organismo de Derechos Humanos a mediados de los '90. Santiago Cueto Rúa (2010) describió estas tres orientaciones a partir de las denominaciones de "dos orígenes" (hijos de desaparecidos y asesinados), "cuatro orígenes" (aceptaban además hijos de exiliados y presos políticos) y "población abierta" (para referirse a quienes no querían hacer restricciones al ingreso).

La apertura que proponen los editores permite repensar a la categoría de víctima desde una nueva perspectiva impulsada por la anulación de las leyes de impunidad por vía parlamentaria en septiembre de 2003 y su posterior declaración de inconstitucionalidad por parte de la Corte Suprema en junio de 2005, así como por la reapertura de los Juicios por Crímenes de Lesa Humanidad con su inicio en la sentencia Simón de agosto de 2006. Es significativo percibir cómo el proyecto editorial va acompañando de alguna forma los juicios, el primer título Versos aparecidos fue publicado en junio de 2007, entre la condena de Miguel Etchecolatz (09/06) y de Christian Von Wernich (09/07). Desde el momento en que las sentencias dejan de ser en el marco de genocidio como en el caso Etchecolatz y pasan a ser por genocidio, se visibiliza la tesis de Daniel Feierstein dado que se reformulan las modalidades de determinación del juicio moral sobre el pasado. Con la utilización de esta figura del derecho internacional la categoría de afectado va a desbordar las discursividades ancladas en el parentesco biológico, tan productivas a lo largo de más de treinta años de lucha contra la impunidad emprendida por los organismos de derechos humanos, para pasar a considerar a todos los ciudadanos argentinos como afectados directos de la destrucción parcial del grupo nacional, dice Feierstein: "si se acepta el dinamismo y la movilidad de los procesos identitarios, en especial los colectivos, al destruir determinadas relaciones sociales e identidades (...) se afecta la identidad de un colectivo, se amputa un elemento identitario que era o podría haber sido parte de lo propio, potencial constituyente de un nosotros",

${ }^{7}$ Feierstein, Daniel, Juicios. Sobre la elaboración del genocidio II, Buenos Aires, Fondo de Cultura Económica, 2015, p. 188. 
Este proceso de ampliación de derechos a partir de la recuperación de la palabra poética y el diálogo intergeneracional se dio por terminado el 10 de diciembre de 2015 con la asunción de un nuevo gobierno neoliberal. Los editores dieron por finalizada la colección en su volumen 20 porque como señalara Derrida, no se escribe el mismo testamento en condiciones de archivo diferente, "la estructura del aparato social de archivación marca desde el principio y del interior la naturaleza, la forma y el contenido del testamento" 8 .

A continuación, analizaremos un acontecimiento que le dio relevancia a la colección y que sirvió para posicionar a los autores y editores dentro del campo literario y político argentino. Nos detendremos en un entrecruzamiento sintomático entre poesía, política y memoria propiciado por el gobierno kirchnerista y que contribuyó a producir un nuevo horizonte de lecturas para la colección y los autores que la integran.

\section{Néstor Kirchner poeta, Joaquín Areta presidente}

Podemos considerar el recurso de la poesía como parte de las operaciones de construcción de un nuevo mito político por parte del kirchnerismo, el cual tendría uno de sus orígenes en el acto de apertura de la Ex ESMA como Espacio de Memoria el 24 de marzo de 2004. Allí la actriz Soledad Silveyra leyó el poema "De repente..." de la poeta desaparecida Ana María Ponce ${ }^{9}$, compañera de militancia de Néstor Kirchner en la Federación Universitaria de la Revolución Nacional (FURN) de la Universidad Nacional de La Plata. Sin embargo, nos detendremos en los efectos producidos a partir de otra lectura realizada por el presidente en 2005 de unos versos de Joaquín Areta, uno de los poetas desaparecidos recuperados por la colección de Los Detectives Salvajes en el quinto volumen.

Me gustaría comenzar realizando una breve reseña descriptiva de los hechos a partir de los cuales se va a desarrollar el presente análisis. El 29 de junio de 1978 el militante de Montoneros ${ }^{10}$ Joaquín Areta, de 22 años, es secuestrado en una cita de la organización y pasa a integrar la lista de los detenidos-desaparecidos víctimas del accionar del terrorismo de Estado que asolaba entonces el país. Esa misma noche, su compañera, Adela Segarra, al ver que su esposo se demora en regresar, decide abandonar la casa que habitaban junto con su hijo de apenas un año y otro compañero, tal como indicaban las pautas de supervivencia de todo militante en la clandestinidad. Escapan con papeles de la organización y documentación personal que podría llegar a comprometerlos en caso de un allanamiento, entre esos papeles Segarra se llevó una libreta de Areta en la que éste escribía poemas hasta poco antes del secuestro.

\footnotetext{
${ }^{8}$ Derrida, Jacques, Mal de archivo. Una impresión freudiana, Madrid, Editorial Trotta, p. 22.

${ }^{9}$ Ana María Ponce fue secuestrada el 18 de julio de 1977 por personal de la Armada y llevada a la ESMA. Fue vista con vida por última vez en febrero de 1978, cuando los marinos le informaron que tendría una entrevista con el director del centro clandestino de detención, Rubén Chamorro. Intuyendo cuál sería su destino, Loli —como se la conocía en la ESMA - dejó a Graciela Daleo, una compañera de detención y sobreviviente de la ESMA, los poemas que escribió en su cautiverio.

${ }^{10}$ Organización político-militar de la izquierda peronista, utilizó la metodología de la guerrilla urbana y la movilización popular, actuó entre 1968 y 1981.
} 
Si bien el material fue utilizado por Segarra como una reliquia de la memoria familiar, siempre que estuvo dentro de sus posibilidades se atrevió a leer y hacer circular los poemas entre compañeros de militancia en el exilio, o con el retorno de la democracia, en las Marchas de la Resistencia o en las conmemoraciones de cada 24 de marzo.

Tres poemas de la libreta fueron publicados por primera vez como parte del libro Palabra Viva, compilación con obras y biografías de 71 detenidos-desaparecidos editada por la Comisión Nacional de Bibliotecas Populares (CONABIP) en 2005. El entonces presidente Néstor Kirchner fue invitado a presentar la antología en la Feria Internacional del Libro de Buenos Aires. Con ese motivo fue que seleccionó para leer un poema de Areta, "Quisiera que me recuerden":
Quisiera que me recuerden sin llorar ni lamentarse, quisiera que me recuerden por haber hecho caminos, por haber marcado un rumbo, porque emocioné su alma, porque se sintieron queridos, protegidos y ayudados, porque nunca los dejé solos, porque interpreté sus ansias, porque canalicé su amor.
Quisiera que me recuerden junto a la risa de los felices, la seguridad de los justos, el sufrimiento de los humildes.
Quisiera que me recuerden con piedad por mis errores, con comprensión por mis debilidades, con cariño por mis virtudes.
Si no es así, prefiero el olvido, que será el más duro castigo, por no cumplir con mi deber de hombre ${ }^{11}$.

Sintomáticamente, luego de la lectura y visiblemente conmovido, aclaró a modo de justificación por la elección: "me sentí absolutamente comprendido en estas palabras que rompen toda temporalidad". En agosto de 2010 Libros de la Talita Dorada publica dentro de su colección Los Detectives Salvajes los poemas de Joaquín Areta bajo el título siempre tu palabra cerca. Solo dos meses después Néstor Kirchner fallece y en medio de un clima de profundo dolor popular y manifestaciones públicas reaparece y comienza a reproducirse a

\footnotetext{
${ }^{11}$ Areta, Joaquín, Siempre tu palabra cerca, City Bell, Libros de la Talita Dorada, 2010.
} 
través de redes sociales y medios de comunicación una grabación de esta lectura que funcionó para los simpatizantes del kirchnerismo como una especie de testamento político. Con posterioridad el libro sigue su propio camino, en 2012 la CONABIP a través del programa Memoria en Movimiento publica y distribuye, de la misma manera que había hecho con los poemas de Ana María Ponce, en escuelas públicas de todo el territorio nacional siempre tu palabra cerca ampliado con material de archivo, fotografías e imágenes. También la lectura de Néstor Kirchner sigue su propio camino, por ejemplo, durante la inauguración en 2015 del Ateneo Néstor Kirchner en Río Gallegos se podía apreciar una gigantografía del poema detrás del panel con los oradores.

Ahora bien, ¿qué nos proponemos con esta breve introducción? Tal vez una cita de una entrevista realizada a Adela Segarra nos ayude a delimitar el problema que nos atañe:

Hay una poesía de Joaquín llamada "Quién de nosotros será", que es premonitoria. Parece escrita para Kirchner. Y a la vez, el escuchar "Quisiera que me recuerden" ahora, en la voz de Néstor después de su muerte, produce entre los dos un acto de simbiosis bastante fuerte y extraño. -No sólo eso, sino que estoy convencida de esa premonición. Porque a pesar de mi ateísmo, de verdad creo que Joaquín y Néstor se conectan en algún lado, se funden. Son señales que te va dando la vida, que te demuestran la existencia de esos encuentros, con cruces, con historias que se atraviesan ${ }^{12}$.

¿Puede la poesía, como toda obra de arte, desde su inactualidad, ser premonitoria? ¿Qué es lo que une a Kirchner y a Areta? ¿En qué plano se produce esta 'simbiosis'? ¿En virtud de qué un acontecimiento es compatible con otro? ¿Qué alcances tiene pensar al sujeto como hijo de sus acontecimientos y no de sus obras? Consideramos que podemos abordar 'lo extraño' del fenómeno a partir de una lectura de Gilles Deleuze, especialmente, a partir de las ideas contenidas en su Lógica del sentido. Consideramos necesario volver sobre este autor que siguiendo la tradición teórica de Henri Bergson permite pensar la memoria desde una perspectiva que difiere de la concepción hegemónica que presentan hoy en día los Estudios de memoria, en el sentido de que si no fuese por el pasado el presente no pasaría, el sujeto necesita para recordar dar un salto ontológico a lo virtual para progresar de lo virtual a lo actual, a la percepción del presente, al espacio que ocupa el cuerpo. Todo lo contrario a una concepción del recuerdo como anclada en el presente y que busca en el pasado aquello que puede servirle. Dentro de esta concepción el presente es siempre pasado que actúa, pero no es, porque es un continuo devenir, mientras que el pasado es, aunque no actúa, para realizarse debe irrumpir en el presente.

El destino del poema de Areta contradice de una manera paradójica, la concepción predominante dentro de la militancia setentista de una poética urgente, de trinchera, comprometida necesariamente con su coyuntura histórica. Como toda obra de arte "Quisiera que me recuerden" excede su tiempo y espacio, el poema sólo puede ser pensado, en este sentido, como inconsciente del pensamiento puro. Pone de manifiesto un exceso significante, un devenir que trasciende el contexto de las condiciones históricas que

12 Enzetti, Daniel, "Lo que hice fue militar sus poesías", Tiempo Argentino, 07 de mayo, 2013. http://www.adelasegarra.com.ar/lo-que-hice-fue-militar-sus-poesias/ 
posibilitaban la efectuación del acontecimiento en la composición del poema. Como primer punto a tener en cuenta vemos que desde una perspectiva deleuziana, sería la obra de arte la que procura el contexto que nos permite comprender correctamente una situación histórica determinada.

Este exceso no quedó abolido por la derrota del movimiento revolucionario a manos de la dictadura militar y los grupos parapoliciales, sino que penetró en tanto acontecimiento la delgada capa de sentido, superficial, sin espesor, que se ubica entre las proposiciones y las cosas (habitando el tiempo del Aión) y siguió rondando el imaginario social en tanto acontecimiento espectral que espera tomar cuerpo. La épica-elegíaca del poema podría entenderse como una profecía, en tanto proyecta su sentido en la adivinación de otro acontecimiento determinado por la profundidad de los cuerpos (contexto histórico), el fallecimiento de Néstor Kirchner.

Deleuze distingue en las cosas, al igual que los estoicos, dos planos que difieren por naturaleza: 1- El de los cuerpos y los estados de cosas que sólo existen en el espacio y en el presente del acto, y 2- El de los incorporales, los atributos lógicos y dialécticos, es decir, los acontecimientos que insisten y subsisten en las proposiciones y en los accidentes corporales. Así es que mientras que los corporales son causas entre sí unos de otros, los efectos que producen, los incorporales, son efectos entre sí, nunca son causas unos de otros, sino casi-causas.

Entre los acontecimientos "se forman relaciones extrínsecas de compatibilidad e incompatibilidad silenciosa, de conjunción y de disyunción muy difíciles de apreciar"13, esta relación de los efectos entre sí va a dar lugar a un sistema de ecos, estribillos y resonancias que van a formar un sistema de signos que Deleuze denomina una casi-causa expresiva. El destino va a hacer que esta casi-causa, es decir, este acontecimiento preindividual, impersonal, repita o reduplique a otro a pesar de su diferencia.

Es precisamente esta convergencia y divergencia simultánea la que se pone de manifiesto en los hechos narrados más arriba, 'lo extraño' para Adela Segarra es justamente esta pieza esencial de la teoría del sentido deleuziana:

Nos referimos [...] a una operación según la cual dos cosas o dos determinaciones son afirmadas por su diferencia [...] No se trata en absoluto de una identidad de los contrarios [...] Se trata de una distancia positiva de los diferentes: no ya identificar dos contrarios a lo mismo, sino afirmar su distancia como aquello que los remite uno a otro en tanto que 'diferentes' ${ }^{14}$.

El sentido, para este filósofo, se encuentra emparentado con el devenir, con lo que fluctúa, nace y muere en el instante, con lo intempestivo y, desde esta perspectiva, el sentido pertenece a otro tiempo, a ese que no se puede representar, pero que constituye la topología del pensar, a este tiempo remite la idea del Aión en oposición a Cronos. Nietzsche trabaja con la misma idea en su Zaratustra y da una visión aproximada a este tiempo en "De

\footnotetext{
${ }^{13}$ Deleuze, Gilles, Lógica del sentido, Barcelona, Paidós, 1994, p. 176.

${ }^{14}$ Deleuze, Gilles, op.cit., p. 179.
} 
la visión y el enigma" cuando el personaje le muestra al gnomo que lo acompaña la puerta del Instante:

desde esta puerta 'El Instante' un largo camino eterno corre hacia atrás, a nuestras espaldas está una eternidad. ¿No debe haber recorrido ya una vez este camino todo lo que puede correr? ¿No debe haber acontecido y pasado por aquí ya una vez todo lo que puede acontecer? Y si todo ha existido ya una vez, ¿qué te parece gnomo éste instante? ¿No debe haber existido esta puerta ya una vez? ¿Y no se hallan todas las cosas tan estrechamente entrelazadas que este instante determina todas las cosas por venir?" 15.

Según Deleuze, lo que el instante extrae del presente como de los individuos que lo ocupan son las singularidades, puntos proyectados hacia pasado y futuro, elementos que constituyen el acontecimiento puro. En este sentido y como segunda aproximación, podemos aprehender la lectura del poema por parte de Kirchner, como la puesta en escena de un actor que en un presente instantáneo hizo surgir un pasado-futuro ilimitado que se presentó en un presente vacio sin más espesor que el de un espejo, la pantalla del televisor con motivo de su muerte, una efectuación en la forma que lo presentiza en el tiempo de Cronos con cada repetición. Tal vez el siguiente gráfico, si tenemos en cuenta que el sentido se encontraría desde esta perspectiva en el límite entre las palabras y las cosas, pueda dar cuenta del movimiento que señalamos:

t AIÓN (Acontecimiento impersonal, preindividual, ideal puro)

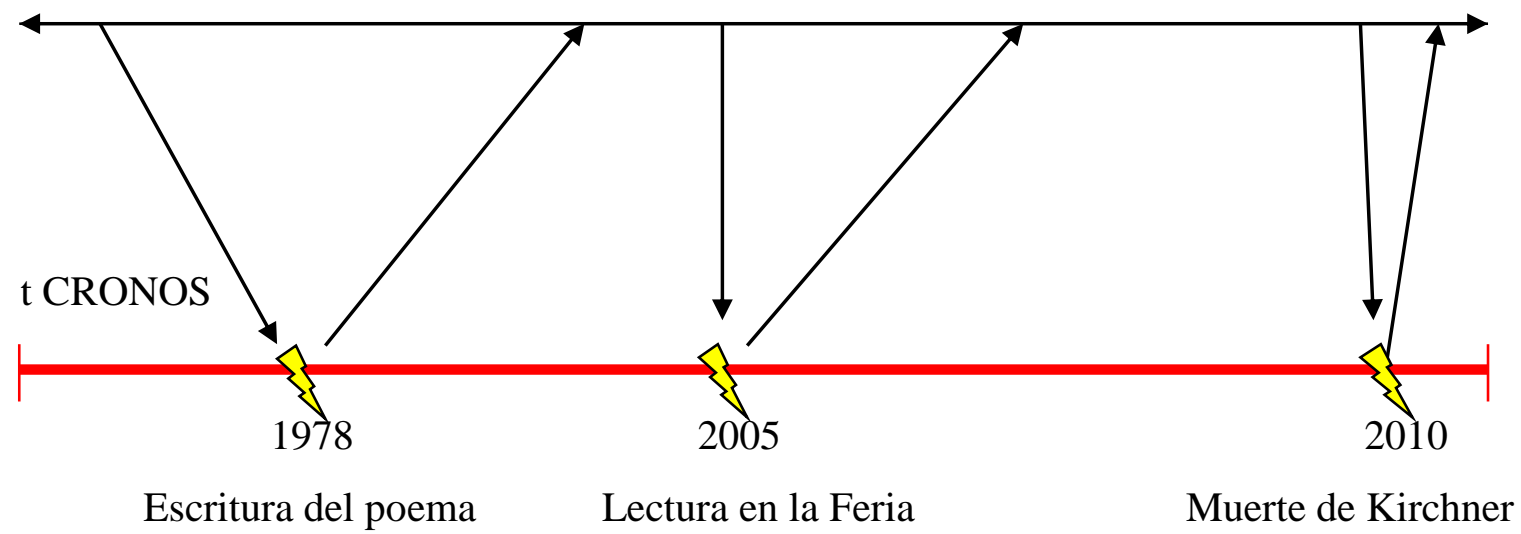

(Causas corporales - Proposiciones expresadas)

${ }^{15}$ Nietzche, Friedrich, Así habló Zaratustra, Buenos Aires, Terramar, 2003, p. 152-153. 
De una manera semejante a lo que señala Borges en su ensayo "Kafka y sus precursores" hay en esa lectura en La Feria un exceso, algo que no se agota en su efectuación, una contra-efectuación que libera al acontecimiento aprisionado en su efectuación, siempre para otras veces. Así como para Borges "cada escritor crea a sus precursores. Su labor modifica nuestra concepción del pasado, como ha de modificar el futuro"16, para Deleuze "lo verdaderamente nuevo no es sólo un nuevo contenido sino el propio cambio de perspectiva por medio del cual lo antiguo aparece bajo nueva luz" ${ }^{17}$. La reproducción virtual de la lectura en la Feria del Libro con posterioridad al fallecimiento de Kirchner activó una superposición mítica de la figura del poeta y del ex-presidente que llevó a los nuevos lectores a buscar en los poemas de Areta nuevos mensajes para el presente, lo cual posibilitó la unión de distintas duraciones a través de la fuerza que se encuentra oculta en lo sensible del poema, en lo que expresa, en las intensidades que lo atraviesan. En ese momento señala Segarra "nació otra cosa, es como que Joaquín y Néstor se fundieron en algo común, cerrando un círculo"18. A partir de entonces es que podemos leer "Quién de nosotros será" como profecía y preanuncio de la presidencia de Néstor Kirchner:

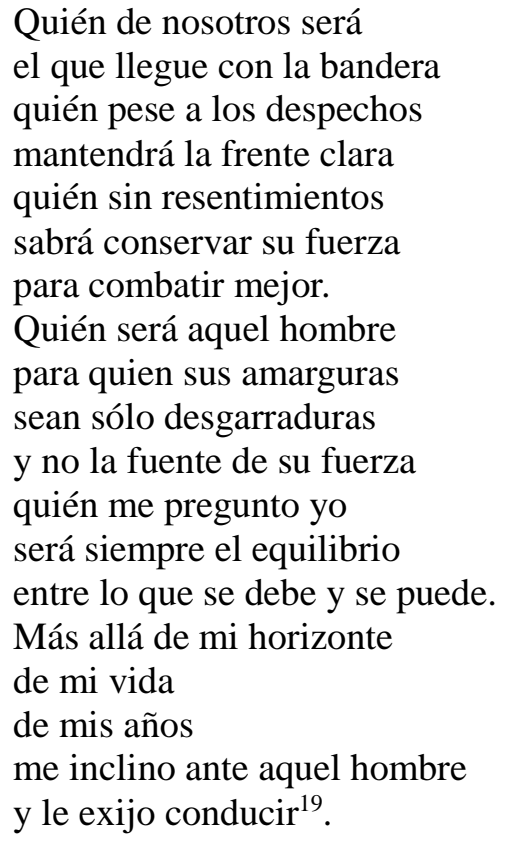

Es sintomático que este poema no haya sido seleccionado para su publicación en la primera edición del libro de Areta, sino que recién vio la luz en la segunda edición con posterioridad a la muerte de Néstor Kirchner.

\footnotetext{
${ }^{16}$ Borges, Jorge Luis, “Kafka y sus precursores”, Obras completas de Jorge Luis Borges, Buenos Aires, Emecé, 1974, p. 712.

${ }^{17}$ Deleuze, Gilles, op. cit., p. 34.

${ }^{18}$ Enzetti, Daniel, op. cit.

${ }^{19}$ Areta, Joaquín, Siempre tu palabra cerca, Buenos Aires, UNSAM, 2011.
} 
Esta idea de Segarra que citamos arriba, circula también en el posfacio escrito para la edición de la CONABIP por Ricardo Forster:

recuperados por una voz venida del sur e impulsada por los vientos patagónicos nos conmovió por su carga anticipatoria, como si la escritura de aquel joven se hubiera juntado con el decir emocionado y lúcido de quien había llegado a la Presidencia de la Nación en nombre de una generación diezmada ${ }^{20}$.

La historia del poema impregna de una sobrevida al militante desaparecido, profeta de la realidad política 30 años después. El poeta Julián Axat, editor de Los Detectives Salvajes, encuentra un mensaje político urgente para los tiempos que corren:

En mi interpretación, la libreta de Joaquín muestra los problemas que todavía predominan en los mecanismos organizacionales peronistas que se heredan a sí mismos "desde arriba" y no construyen cuadros integrales desde lo humano-sensible que dinamicen su propia estructura 'desde abajo' 21 .

La reactualización con posterioridad a la muerte de Néstor Kirchner de la lectura del poema de Areta a través de las redes sociales y los medios de comunicación pone de manifiesto la univocidad del Ser planteada por Deleuze, dado que fue posible percibir dos acontecimientos diferentes e incompatibles como algo que aconteció en el mismo nivel ontológico. Bajo esta misma diferencia las ideas pueden relacionarse con otras diferencias sin necesidad de un vínculo trascendente, como ocurre con la identidad en la filosofía que Deleuze denomina de la representación, y que se propone minar en ese movimiento que llama de inversión del platonismo y que encuentra ya presente en el estoicismo.

Desde esta perspectiva entendemos que el Ser, siendo uno, va a poder expresarse en multiplicidades. Es un ser que se dice en sus diferencias. Una experiencia que excede al sujeto. A la hora de elegir un poema para presentar la antología entendemos que se puso en movimiento en la intuición del lector, una salida de su propia duración para encontrarse con otras duraciones. Areta y Kirchner unidos por la efectuación del acontecimiento ideal en dos tiempos diferentes, son dos melodías de una misma composición. En ese exceso significante que solo adquiere sentido 5 años después, se expresa una singularidad que se proyecta a futuro y a pasado constituyendo el acontecimiento puro.

El movimiento entre estas fuerzas que giran alrededor de estos nombres propios conectados por el poema van a constituir el proceso de individuación de ambos. Kirchner se definirá a través de las palabras de Areta, Areta seguirá desarrollando una identidad incluso después de su muerte, eternamente relacionado con Kirchner a partir de la efectuación del poema en tanto acontecimiento con su propio devenir. Ambos en el tiempo de Aión dan cuenta de la univocidad del Ser. Estas fuerzas en relación van a dar como resultado un individuo que diferirá de las dos series, será una construcción precaria siempre susceptible

\footnotetext{
${ }^{20}$ Forster, Ricardo, "El poeta, un viento del sur y los sueños ya soñados" en Joaquín Areta, Siempre tu palabra cerca, Buenos Aires, UNSAM, 2011, p. 56.

${ }^{21}$ Axat, Julián, “Apuntes sobre la libreta de Joaquín Areta y la herencia kirchnerista”, 2011, http://lateclaene.wix.com/latecla-ene\#! axat-julin/c1knp
} 
de nuevas transformaciones a través de un espectro eterno de nuevas actualizaciones que plasmen su impronta. Joaquín Areta presidente, Néstor Kirchner poeta.

Para terminar, me gustaría retomar el problema que surge a la hora de dar cuenta del acontecimiento a través del lenguaje. Exceso del significante, lugar vacío móvil y defecto del significado, ocupante sin lugar; ambos son una diferencia simultánea, mientras que el primero encuentra cualquier aspecto de sentido, el segundo no implica el sentido sino el concepto. Esto es 'lo extraño' a lo que hacía referencia Segarra, la imposibilidad de dar cuenta plena del acontecimiento ideal impersonal, de estos efectos incorporales que Deleuze propone expresarlos con el impersonal 'se' a la manera blanchotiana o a través de infinitivos o participios. Este acontecimiento-sentido posibilita que el poema acceda a un campo trascendental y revela la instancia paradójica que establece conexiones entre las palabras y las cosas: el fantasma, a la manera lacaniana, como punto aleatorio, casilla vacía y elemento supernumerario, elemento irreductible a las proposiciones y a las cosas, que sobra y que falta y que se encuentra siempre en la superficie. Fantasma que pone de manifiesto la impotencia del hablante y la potencia del lenguaje en la paradoja de la proliferación indefinida que Deleuze analiza en la "Quinta serie: Del sentido":

dada una proposición que designa un estado de cosas, siempre puede tomarse su sentido como lo designado de otra proposición. Si convenimos en considerar la proposición como un nombre, sucede que todo nombre que designa un objeto, puede convertirse a su vez en objeto de un nuevo nombre que designe su sentido: dado $\mathrm{n} 1$ remite a $\mathrm{n} 2$ que designa el sentido de $\mathrm{n} 1, \mathrm{n} 2$ a n3, etc 22 .

De ahí que la única forma de evitar esta regresión por parte de quienes analizan el acontecimiento que nos ocupa, haya sido la de fijar la proposición a partir de frases indeterminadas que se asoman a la orilla de lo inexpresable, para extraer así un sentido: 'lo extraño' que 'cierra un círculo' en Adela Segarra, el 'puente generacional invisible' en Julián Axat o la posibilidad de 'soñar sueños ya soñados por otros soñadores' según Ricardo Forster, intentan dar cuenta a través de un esoterismo proposicional de esa capa superficial de sentido que nos sacude 'de golpe' con la efectuación de un acontecimiento, como dados arrojados al azar por un cubilete, como dijo el poeta César Vallejo en el "Himno a los voluntarios de la República":

"Todo acto o voz genial viene del pueblo y va hacia él, de frente o transmitido por incesantes briznas, por el humo rosado de amargas contraseñas sin fortuna" 23

A continuación, veremos cómo la superposición entre la figura de Joaquín Areta y Néstor Kirchner condicionó de alguna manera la recepción de la colección y contribuyó a la

\footnotetext{
${ }^{22}$ Deleuze, Gilles, op. cit., p. 50.

${ }^{23}$ Vallejo, César, Obra poética completa, Caracas, Biblioteca Ayacucho, 1979, p.271.
} 
polémica que se desató con la presentación de la primera antología de la colección, a sólo ocho días de la muerte del ex presidente.

\section{Hamlet, sus hermanos y la guillotina}

En el contexto de las repercusiones por la muerte del ex presidente Néstor Kirchner, Los Detectives Salvajes publica su primera antología Si Hamlet duda le daremos muerte. Antología de poesía salvaje, que reúne a $49^{24}$ poetas argentinos de distintos puntos del país. El libro fue presentado el 04 de noviembre de 2010 en el Centro Cultural Islas Malvinas de la ciudad de La Plata. Con ese motivo se instaló una guillotina para poner en funcionamiento una performance que excedió el ámbito de la propia presentación. Lúdicamente se guillotinó un ejemplar de Horla City (Emecé, 2010), la poesía reunida de Fabián Casas.

Éste libro, que rápidamente agotó su primera tirada de 5000 ejemplares, se convirtió en un éxito de ventas para Emecé, fenómeno que hacía tiempo no provocaba un poeta contemporáneo vivo. Emecé funciona como una marca de prestigio dentro del Grupo Planeta, de esta manera coincidimos con la apreciación que realiza Badagnani respecto de la operación Casas:

luego de haber adquirido y vaciado el sello editorial, al holding editor solo le quedó la utilización de la marca como forma de diferenciar productos masivos de otros que consideró más válidos (que se mantienen por una cuestión de prestigio) porque apuntan a un público más restringido. Así el éxito de Casas es doble: no solo logra la aceptación y el contrato por parte del holding más poderoso, sino también una edición que niegue esta propia inscripción ${ }^{25}$.

Ahora bien, nos interesa detenernos en la polémica que ocasionó esta presentación. En primer lugar, entre los poetas y escritores cercanos a la formación cultural nucleada alrededor de la Colección, y en segundo lugar en las críticas de poetas representativos de la poesía de los'80 y los '90. Entendemos que este acto afectó profundamente las lecturas posteriores que se hicieron de los títulos y de los poetas de la colección.

Como primera aproximación, podemos intentar interpretar qué significados se pusieron en juego con ese acto performático, ya anunciado en los prólogos y los epílogos de la antología por parte de Julián Axat, Juan Aiub, Emiliano Bustos y Nicolás Prividera, a partir de las críticas que el grupo realiza a la denominada poesía de los ' $90^{26}$, en un intento por delimitar al menos cuatro puntos compartidos por todos los participantes:

\footnotetext{
${ }^{24} \mathrm{Si}$ bien los poetas son 52 y se ofrecen breves datos personales de cada uno, hay 3 que son heterónimos de Julián Axat: Leandro Daniel Barret, Rodrigo Zubiría y Rosario González Sánchez.

${ }^{25}$ Badagnani, Adriana, "Los detectives jacobinos y la poética de los hijos de desaparecidos", Estudios de Teoría Literaria. Revista digital Año 3. № 6, 2014, p. 43-55.

${ }^{26}$ Según Marina Yuszczuk la denominación "poesía de los noventa" remite a aquellas poéticas que pueden considerarse como emergentes a partir de la definición de Raymond Williams. Se trata de "los nuevos significados y valores, nuevas prácticas, nuevas relaciones y tipos de relaciones que se crean continuamente" en el marco del proceso cultural, y que se definen de modo relacional con respecto a los elementos de la cultura dominante. En ese sentido, se plantea como
} 
1) En primer lugar, leemos una crítica al objetivismo como estética hegemónica en la poesía argentina de los '90 y sus epígonos.

2) En segundo lugar, una acusación a los reducidos circuitos de producción, difusión y circulación que pretendería representar toda la actividad poética en una especie de corredor Buenos Aires-Bahía Blanca-Rosario, endogámico y autolegitimado a partir de los vínculos entre academia, periodismo cultural y poetas.

3) Se acusa a estos poetas de la construcción de un presente eterno que no se interroga por la historia ni por el futuro. Emiliano Bustos denuncia una adolescencia inactual en estos poetas, producto de la comodidad que los ampara en el éxito.

4) La falta de densidad política amparada en una falsa anti-política o no política que se relaciona con una estética de la derrota, visualizada en la tradición por los proyectos setentistas y en el presente por la superficialidad menemista y sus continuidades después de 2001.

Nos preguntamos qué sentido tienen o cuan atinadas son estas hipótesis más allá de posicionar, en el campo literario, con la performance, prólogos, epílogos y declaraciones públicas, al grupo de poetas nucleados en la colección a partir de una escenificación del antagonismo. Es interesante remarcar que todo guillotinamiento, en tanto acto que pretende fundar una nueva justicia, se orienta siempre hacia un nombre (un autor singular), y en este acto fundante se simbolizaría el nacimiento de una multiplicidad polifónica de poetas, los integrantes de la antología. El guillotinamiento funciona como la negación de un orden para la poesía y como un límite a la hegemonía objetivista.

Podemos interpretar esta acción simbólica como un movimiento de politización de un sector del campo poético que cuestiona, como ya veremos en las respuestas de otra formación cultural, lo social-naturalizado, tal como señala Ema López (2007), además de que posibilita reintroducir en la política, lo político y desplaza las fronteras entre lo político y lo social.

En primer lugar destacamos que con el guillotinamiento del libro de Casas se hizo lo impensable, que remarca de manera reiterativa Fernando Alfón en su primera intervención ${ }^{27}$ : "se guillotinó un libro". Este acto jacobino rompe el consenso liberal de apropiación del objeto cultural libro y recupera un imaginario mítico emancipador que entronca con la tradición anti-intelectual que remite al "Alpargatas sí, libros no" que según cuentan las crónicas de la época gritaron los obreros de Berisso frente a la Facultad de

emergente en relación a las líneas vigentes hasta fines de la década del ochenta en el subcampo de la poesía (que verdaderamente constituye un espacio separado dentro del campo literario, al menos en su aspecto diacrónico): el neobarroco y el neorromanticismo. El surgimiento del objetivismo, estrechamente vinculado al Diario de poesía que comienza a publicarse en el '86, representa una línea de ruptura que por un lado impugna los valores implícitos en estos movimientos y por otro, da inicio al armado programático de una tradición que funcionará como eje para los diversos posicionamientos de los poetas a lo largo de la década". Yuszczuk, Marina, Lecturas de la tradición en la poesía argentina de los noventa. Tesis de doctorado, La Plata, 2011, p. 6.

${ }^{27}$ Los editores comenzaron a publicar en su blog las repercusiones de la presentación. Fernando Alfón realizó una reseña el 05 de noviembre e incitó el intercambio y el debate con un texto denominado "La guillotina". Allí planteaba su asombro y fascinación ante el símbolo, señala las continuidades entre el título de la antología y la puesta en escena (podríamos agregar también las reminiscencias de la Cesárea Tinajero en la obra de Bolaño), y lleva su interpretación al problema de las influencias literarias y los padres-autoridad que son constitutivos de cada poeta o escritor. 
Humanidades y al Rectorado de la UNLP el 17 de octubre de 1945 cuando reclamaban por la liberación de su líder político Juan Domingo Perón.

La construcción de la escena del guillotinamiento hace visible el desacuerdo, siguiendo a Jacques Ranciére leemos esta intervención como una escenificación de prácticas de poder naturalizadas $^{28}$. Es interesante remarcar que el autor no reduce el desacuerdo a un Acto de habla, tal como se demuestra en este caso. La formación cultural que gira en torno a la colección cuestiona una determinada división de lo sensible que recupera sin buscarlo una visualización del antagonismo que los enfrenta a otra formación cultural hegemónica, la de los poetas Irene Gruss, Jorge Aulicino y Jorge Fonderbrider ${ }^{29}$ que no tardan en responder.

E1 26 de diciembre de 2010 Gruss publica "Acerca de guillotinas y destornilladores"30 un comentario en su blog personal haciendo referencia al artículo que Diego Erlan publica en la Revista $\tilde{\mathrm{N}}^{31}$ pero sin haber leído la antología. Por lo tanto, cuestiona únicamente el hecho de la guillotinada del ejemplar de Casas en la presentación en La Plata, a la cual confunde con la presentación en el Espacio Cultural Nuestros Hijos de la Ex Esma. Lo considera un acto innecesario "gracioso no es; novedoso, menos; ¿escandaloso?, ¡vamos!". En todo caso sugiere que a una estética se la mata escribiendo algo mejor y pone el ejemplo de César Vallejo y la publicación de Trilce, cuando quiso superar el agotamiento del Modernismo. Además, considera que Casas no es objetivista y rebaja su primer poemario a una fotocopia de Carver, Giannuzzi y Aulicino. En todo caso celebra que un libro de poesía se encuentre entre los más vendidos de 2010, algo inédito para el género. A continuación, participan del intercambio con comentarios de distinto tenor: Jorge Aulicino, Jorge

\footnotetext{
${ }^{28}$ Rancière, Jacques (1996) El desacuerdo. Filosofía y Política. Nueva Visión. Buenos Aires. Según el autor, la política aparece cuando el orden de la dominación es interrumpido. Los "excluidos" e "invisibles" hacen público "la parte de los sin parte" en el corazón de ese orden policial. Es esta revelación la que subvierte el orden y nos ubica ante la política, bajo el argumento o principio de igualdad: somos todos iguales. Hasta que esos excluidos no hacen público ese argumento no representa una amenaza para el orden. Aquella visibilidad marca el inicio de la política y el surgimiento de lo que Ranciére denomina como "desacuerdo". La política es el resultado de la puesta en escena de este desacuerdo o conflicto entre aquellos a los que les era negada la palabra, pero la usurpan para demostrar esa exclusión. Ranciére recurre a la noción de desacuerdo como el encuentro de dos lógicas incompatibles que entran en conflicto. El desacuerdo es una situación, un proceso de argumentación, en la que está en pugna la significación y que no se reduce al acto del habla sino a todo tipo de acto público.

${ }^{29}$ Los tres se iniciaron en el taller literario de Mario Jorge De Lellis en la década de los '60. Aulicino y Fondebrider formaron parte del Consejo de redacción de Diario de poesía, Aulicino formó parte además de la revista 18 whiskys, ambas publicaciones centrales para pensar la poesía argentina contemporánea. Los autores además forman parte de los catálogos de prestigiosas editoriales de poesía: Libros de Tierra Firme y Ediciones del Dock. En el marco de la polémica participaban o trabajaban en la Revista $\tilde{N}$, suplemento de cultura del diario Clarín, principal medio de oposición al gobierno de Cristina Fernández de Kirchner.

${ }^{30} \mathrm{http}: / /$ elmundoincompleto.blogspot.com.ar/2010/12/acerca-de-guillotinas-y.html

31 Erlan, Diego, “¿La poesía de los 90 a la guillotina?”, Revista $\tilde{N} \mathrm{n}^{\circ} 378,24 / 12 / 2010$, p. 24:“Un fantasma recorre la poesía argentina. Es el espectro del pasado y del presente, de la memoria y del olvido. Las muertes de la historia todavía sangran. En la presentación del libro Si Hamlet duda le daremos muerte (Libros de la Talita Dorada), apuntaron a su objetivo. "Ayer asistí a un acto donde se guillotinó un libro", escribió Fernando Alfón. "Conservo un pedazo del libro ejecutado. Escribo este testimonio asaltado, aún, por la fascinación y el asombro", sigue el poeta incluido en el libro, hasta reconocer después que las guillotinas demandan nombres propios y por eso lo dice: el libro "ejecutado" fue Horla City, de Fabián Casas. ¿Qué representaba? El objetivismo. Emiliano Bustos explica: fue la estética que dominó parte de la escritura poética de los últimos 20 años. Julián Axat y Juan Aiub, en la introducción, se quejan de que el campo literario actual es funcional a la derrota (de los 70), gestionando la consagración de algunas voces, mientras obtura la difusión de otras. Eso se puede discutir. Y este es un debate que viene creciendo y es fundamental. El problema es que el gesto (la guillotina sobre el libro) arrastre el recuerdo a los tiempos más oscuros de la historia”
} 
Fonderbrider, Anahí Mallol, José María Pallaoro, Julián Axat, Nicolás Prividera, Demetrio Iramain y Sebastián Lalaurette, entre otros visitantes anónimos o que se identifican.

Luego de una lectura minuciosa de la polémica nos interesa sintetizar y analizar los efectos que el intercambio produjo en Gruss, Aulicino y Fonderbrider, en sus comentarios es evidente la situación de poder que detentan y que de alguna forma valida las críticas vertidas por los autores de la antología:

1) Manifiestan una total falta de interés por discutir el valor puramente estético de la antología, reduciendo el libro al acto performático de una de las presentaciones. Aulicino: "Lo de la guillotina es de muy siniestro gusto", "fue una acción marketinera lamentable"; Fonderbrider: "esto de guillotinar libros es lisa y llanamente haber adoptado las fórmulas que generalmente se le atribuyen al enemigo (y no me refiero al enemigo poético) ¿Qué, ahora viene el terror?".

2) Con el debate público que propusieron Los Detectives Salvajes algo se rompió en el "entre nos" literario, síntoma de ello es el profundo malestar que exteriorizaron a través del agravio personal y la censura. El ámbito de la poesía, por ser tan reducido, reacciona rápidamente ante quien cuestione el consenso en el que imaginariamente pretende gravitar. Gruss: "curioso es que justo entre los presentes de dicho acto para nada simbólico (...) haya estado nada menos que Emiliano Bustos...Pareciera que nacieron de un repollo"32.

3) En el transcurso de los intercambios se produjo una superposición interesada entre la esfera política y el hecho de reclamar pensar una política de la literatura o una lectura crítica de los poemarios de la generación de los '90. Fonderbrider: “¿Cómo es que Casas no deja emerger a estos preclaros poetas que escriben en cuanta revista pueden (sea de izquierda, de derecha o de nada), que viven de las migajas que les tira el degradado PC peronizado, que se cargan a quien sea con tal que se los tenga en cuenta? (...) ¿Por qué esos Robespierre de pacotilla no se irán a lavar el culo?"; Gruss: "La pucha, cuántos anónimos existen. Después se quejan de no poder tener identidad propia. Y mucho menos hacerse un nombre".

4) Al apelar a cierto "decoro" o "buen gusto" para oponerse a un léxico impropio para el ámbito de la poesía como "picana" o "ESMA". Gruss: "Acabo de pasar por el blog (...) y casi me caigo pa'tras: ¿Guillotina o submarino?; ¿Revolución Francesa versus Casa, en lugar de los que dominaron la ESMA y otros campos? ¡H.I.J.O.S. vs. Casas?; ¿marketing en la ESMA? (...) Disculpen, pero esto me sobrepasa".

5) Los autores denuncian incompatibilidad entre militancia y escritura, lo cual lleva a pensar en cierta defensa del poeta en la torre de marfil. Aquí es muy gráfico el comentario de Demetrio Iramain, editor de la revista ¡Ni un paso atrás! de la Asociación Madres de Plaza de Mayo:

A que ninguno de quienes critican la guillotinada del libro de Casas se anima a presentar sus libros de poemas en la ex-ESMA, en el espacio de las Madres dentro de ese predio de muerte ganado para la vida. Y ya que estamos, el diario Clarín, por caso, guillotina todos los días la verdad, la inteligencia, la belleza, la poesía del pueblo, sin el gesto visible de las hojas tajeadas. Lo de amasijar el libro aquel fue un saludable gesto de provocación como no veo en la poética

\footnotetext{
${ }^{32}$ Emiliano Bustos es hijo del poeta y militante del PRT desaparecido Miguel Ángel Bustos.
} 
argentina hace tantísimos años. La poesía oficial parece el Poder Judicial: vuelve la "democracia", arrasa Menem, pasa la rebelión de 2001, viene el kirchnerismo, y los jueces permanecen inmutables, apretados contra sus sillones.

La respuesta de Gruss acentúa la idea del ítem:

Demetrio, tu bajada de línea, me parece, no debate la entrada que generó esta suma de comentarios. ¿Animarse o no animarse a presentar un libro en la ESMA? Cómo no. El tema es que quienes lo hicieron un mes antes iguillotinaron "simbólicamente" un libro! Me pregunto por qué no lo hicieron también en la ESMA. ¿Por respeto a la vida o a los muertos que todavía huelen y duelen ahí? ¿Y qué catzo tiene que ver Casas o la poesía de los '90 con todo esto? Vaya a saber.

Interpretamos estas repercusiones de la presentación del libro como un acontecimiento político, en el sentido que señalara Ema López: "la actividad política manifiesta la pura contingencia del orden, la igualdad de cualquier ser parlante con cualquier ser parlante"33. La visibilización de los poetas como sujetos políticos requirió de una identidad negativa, guillotinadora, junto con la fundación de un sujeto a partir de un daño (un sujeto negado u olvidado por la comunidad) que sostiene un argumento de igualdad. En este caso poetas emergentes, hijos de desaparecidos o asesinados, que ya habían sido olvidados en el plano civil a partir de las leyes de impunidad de finales de los '80 y que, en el presente, una vez recuperados sus derechos a partir de las políticas en derechos humanos impulsadas por los gobiernos kirchneristas (2003-2015) discuten y quieren ser leídos como pares por los poetas reconocidos. Que la polémica se haya dado en el contexto de la muerte del ex presidente, con la profusa circulación mediática de la lectura que éste hiciera del poema de Joaquín Areta, permitió interpretar la lógica propia del campo poético en sincronía con la lógica del campo de la política, produciendo múltiples malentendidos o sorderas interesadas que buscaban invisibilizar, como vimos, una posición de poder.

\section{Cierre}

Luego de repasar este fenómeno se pone en evidencia lo que Adriana Badagnani señala a propósito de la poesía de los hijos:

se erige en la intersección de los campos de los derechos humanos, la política y la literatura; la lógica diferenciada de funcionamiento de esos espacios genera en los poetas tensiones que parecen querer salvarse con gestos públicos polémicos como forma de lograr el lugar propio ${ }^{34}$.

\footnotetext{
${ }^{33}$ Ema López, José Enrique, “Lo político, la política y el acontecimiento”, Revista Foro Interno, n 7, 2007, p. 62.

${ }^{34}$ Badagnani, Adriana, op. cit., p. 43-55.
} 
Tal como vimos en los apartados anteriores, hay un intento de llevar discusiones del ámbito de los derechos humanos a la literatura, o de la poesía a la acción política que en definitiva consiste en repensar nuevos entrecruzamientos entre arte y vida. En este sentido estaríamos frente a un colectivo de poetas que intenta recrear la vanguardia política de sus padres a partir de un neo vanguardismo artístico que en lugar de romper con la tradición heredada necesita reponerla, dado que fue desaparecida, para permitir entablar los vínculos sociales, políticos y artísticos que el genocidio ejemplificador vino a destruir.

En el caso de la lectura que realizara Néstor Kirchner del poema de Joaquín Areta pudimos ver de qué manera un trabajo de memoria determinado produce efectos sociales impensados para quienes lo promovieron y excede el campo literario para desencadenar una serie de implicancias políticas concretas ineludibles a los sujetos históricos que habitan el presente de su efectuación, por ejemplo, el posicionamiento de los integrantes de la formación cultural dentro del campo literario argentino.

\section{Referencias bibliográficas}

\section{Fuentes impresas}

Areta, Joaquín, Siempre tu palabra cerca, City Bell, Libros de la Talita Dorada, 2010.

Areta, Joaquín, Siempre tu palabra cerca, Buenos Aires, UNSAM, 2011.

Axat, Julián, "El hijo y el archivo" en $9^{\circ}$ Conferencia bianual de la International Association of genocide scholars "Genocidio, verdad, memoria y elaboración", Universidad de Tres de Febrero, 2011.

Borges, Jorge Luis, Obras completas de Jorge Luis Borges, Buenos Aires, Emecé, 1974.

Cueto Rúa, Santiago, "El surgimiento de la agrupación HIJOS La Plata. La discusión por quienes son las víctimas del terrorismo de Estado", Sociohistórica / Cuadernos del CISH, n 27, 2010.

Dalmaroni, Miguel, "La obra y el resto (literatura y modos del archivo)" en TELAR. Revista del Instituto Interdisciplinario de Estudios Latinoamericanos, Facultad de Filosofía y Letras, Universidad Nacional de Tucumán, vol. 7, 2009

Da Silva, Ludmila, No habrá más flores en la tumba del pasado, La Plata, Ediciones Al Margen, 2001.

Deleuze, Gilles, Lógica del sentido, Barcelona, Paidós, 1994.

Derrida, Jacques, Mal de archivo. Una impresión freudiana, Madrid, Editorial Trotta.

Erlan, Diego, “¿La poesía de los 90 a la guillotina?”, Revista $\tilde{N}$ n 378, 24/12/2010. 
Feierstein, Daniel, Juicios. Sobre la elaboración del genocidio II, Buenos Aires, Fondo de Cultura Económica, 2015

Forster, Ricardo, "El poeta, un viento del sur y los sueños ya soñados" en Joaquín Areta, Siempre tu palabra cerca, Buenos Aires, UNSAM, 2011.

Jelin, Elizabeth, Los trabajos de la memoria, Madrid, Siglo XXI, 2002.

Nietzsche, Friedrich, Así habló Zaratustra, Buenos Aires, Terramar, 2003

Rancière, Jacques, El desacuerdo. Filosofía y Política. Nueva Visión. Buenos Aires, 1996.

Tavernini, Emiliano, "Procesos de recuperación y negación de la voz filial en las poéticas de hijos de desaparecidos. La colección de poesía Los Detectives Salvajes", Cuadernos de Aletheia $n^{\circ} 2$. H.I.J.O.S. 20 años, Universidad Nacional de La Plata, octubre 2016, p. 40-52.

Vallejo, César, Obra poética completa, Caracas, Biblioteca Ayacucho, 1979.

\section{Fuentes digitalizadas}

Axat, Julián, "Apuntes sobre la libreta de Joaquín Areta y la herencia kirchnerista", 2011, http://lateclaene.wix.com/la-tecla-ene\#!axat-julin/c1knp

Axat, Julián y Aiub, Juan, "Proyecto 'Detectives por la memoria", www.coleccionlosdetectivessalvajes.blogspot.com, 2007.

Badagnani, Adriana, "Los detectives jacobinos y la poética de los hijos de desaparecidos", Estudios de Teoría Literaria. Revista digital Año 3. № 6, 2014.

Enzetti, Daniel, "Lo que hice fue militar sus poesías", Tiempo Argentino, 07 de mayo, 2013. http://www.adelasegarra.com.ar/lo-que-hice-fue-militar-sus-poesias/

Yuszczuk, Marina, Lecturas de la tradición en la poesía argentina de los noventa. Tesis de doctorado, La Plata, Universidad Nacional de La Plata, 2011, http://www.memoria.fahce.unlp.edu.ar/library?a=d\&c=tesis\&d=Jte742 